\title{
Do reluctant voters vote less accurately? \\ The effect of compulsory voting on party-voter congruence in Australia and Belgium
}

Australian Journal of Political Science, 52, 2017, in press.

(C) Australian Journal of Political Science, 2017

\begin{abstract}
We know compulsory voting is associated with higher levels of electoral turnout. It has been suggested, however, that this leads to a trade-off with the quality of the vote, i.e., the ideological congruence between voters and the party they vote for. In this study, this claim is investigated using data from the 2007, 2010, and 2013 elections in Australia. We also include a comparison with two recent elections in Belgium, another country with compulsory voting and almost equally high turnout figures. The results show that reluctant voters vote less ideologically congruent, but that this effect is mediated by the lower levels of political knowledge and political interest of these voters. However, this does not lead to less ideologically congruent election results at the aggregate level and compulsory voting does not seem to have an impact on electoral results. We speculate that in future studies on compulsory voting, it is important to make a distinction between reluctant voters, and those who take a strong hostile stand on the electoral process.
\end{abstract}

Keywords: Australia, Belgium, compulsory voting, ideological congruence 


\section{Introduction}

In the 2016 elections, 91.0 per cent of all registered voters in Australia effectively turned out to vote, a slight decrease compared to the 93.2 per cent that was recorded in 2013. Because of this incredibly high turnout figure, Australia stands out in international comparisons on voter turnout. Self-evidently, the rather strict regulations on compulsory voting in Australia can be held responsible for this exceptionally high turnout rate (Hill 2015). Looking at international comparisons, only Belgium has a similar position, with a strict compulsory voting legislation, and an accompanying and rather stable turnout rate of 89.4 per cent (Quintelier et al. 2011). ${ }^{1}$ The Australian system of compulsory voting has been the topic of an ongoing normative debate, but in the current analysis, our goal is to investigate a more empirical counter-argument. It has been argued that while compulsory voting indeed boosts turnout rates, it does so by forcing the least interested and the least knowledgeable to go out and cast a vote (Selb and Lachat 2009). If that is the case, the 'quality' of the vote inevitably suffers, as it might be assumed that these reluctant voters will cast their vote in a more random manner. Elections only contribute to the representative quality of democracy if citizens indeed are able to identify the party that is closest to their own demands and preferences. We know from previous research that resources like knowledge, interest, sophistication or access to media information help citizens to identify this closest party and it can be argued that this party is indeed best able to represent their interests (Lau and Redlawsk 2006). The obvious assumption then would have to be that while the Australian system of compulsory voting manages to boost voter turnout, the voters that only vote because of this legal obligation will not be able to cast a congruent vote, for the simple reason they are not all that interested in politics. Investigating this claim, self-evidently, is directly relevant for the current debate on compulsory voting. If more reluctant voters indeed would not be able or willing to vote in a democratically meaningful manner, the conclusion would have to be that, no matter what are the intentions, the current system of compulsory voting does not help these groups to get their voice heard within the political decision-making process. High turnout figures do not help to achieve the goal of democratic representation if the vote itself is not meaningful and not well-informed (Lau et al. 2014: 240).

Given the very high turnout rate in Australia, it is not possible to obtain any reliable figures on the limited number of people that do not show up: the same reasons that explain why actors do not participate in elections also inhibit their participation in electoral survey research. Therefore this study will rely on the self-reported willingness to vote, as expressed in voter 
surveys. Earlier research has shown that the group of hostile voters - that says it would not vote without compulsory voting - and the group of reluctant voters - indicating probably not to vote anymore without obligation -have exactly the same background characteristics as the group of non-voters that can be observed in countries without compulsory voting (Hooghe and Pelleriaux 1998; Jackman 1999). It is a reasonable assumption therefore that these groups of reluctant and hostile voters closely mirror the groups that in fact do not participate in a system of voluntary voting. In order to increase the reliability of the findings, data from the last three available election studies in Australia will be used, thus avoiding the pitfall that any results might be due to specific electoral circumstances. A counter-argument might be that the Australian electoral context is not an ideal context to conduct this test. The effective number of parties in the Australian political system is rather low in international comparisons (although it has risen sharply in the 2013 elections), and in these circumstances it is not all that difficult to identify the party that is closest to one's own preference, thus leading to an ideologically congruent vote. It could therefore be argued that in the Australian context, even reluctant and hostile voters should not experience too much trouble in identifying the closest political party (Powell 2009). The vote choice process indeed becomes more complicated as the number of parties that are competing, is higher (Lau et al. 2014). To include a stricter and more conservative test, the Australian figures will be compared with results from Belgium. In this regard, Belgium can be considered as a similar case, as it is one of the few countries in the world combining compulsory voting with free and fair elections and a turnout in the 90 per cent range. The major difference between the two cases, however, is that the Belgian party system is extremely fragmented, with the effective number of parties ranging around 10 (Deschouwer 2012). For the Belgian voter, therefore, it is a much more challenging task to identify the closest political party (Dassonneville 2012), so the question becomes whether in these more extreme circumstances too, the reluctant and hostile voters are still successful in identifying the closest political party. The guiding assumption in the analysis is that those who express less willingness to vote if compulsory voting would be abolished, will be less successful in casting an ideologically congruent vote. For Belgium, data of two electoral cycles are used, thus avoiding any effects that are just due to the context of one specific election.

In this paper, first the literature on the effects of compulsory voting and its consequences for the quality of the vote is reviewed, before presenting the data and our method of analysis. In the concluding section it is reflected on what the results tell us about compulsory voting in Australia, but also about the process of vote choice itself. 


\section{Literature}

\section{Compulsory voting}

There can be little doubt that compulsory voting effectively boosts voter turnout. Especially if this legal obligation is rather strictly enforced, like in Australia, a large group of citizens takes part in elections while they would not do so in other circumstances (Hooghe and Kern forthcoming; Louth and Hill 2005; Hill 2010). Rather famously, in a spring 2016 speech, president Obama praised the Australian system of compulsory voting as an example for the United States, as compulsory voting indeed has a huge mobilising effect on the electorate. Some empirical research has shown that because of compulsory voting, leftist parties are slightly advantaged with regard to electoral outcomes (Mackerras and McAllister 1999; Fowler 2013), although it has to be noted that this effect is not found in all available election research. This paper, however, aims to investigate another potential result of compulsory voting: the accuracy of the vote decision process. The alleged goal of elections is to ensure that elected officials and the policy they pursue accurately represent the preferences of the citizens (Przeworski et al. 1999). The more the preferences of elected officials and parties deviate from the preferences of the population, the weaker the representative function of elections is. One could assume that a high degree of ideological congruence between voter and party is most easily achieved in conditions of high voter turnout. Non-participation in elections is highly selective, the most likely result of low turnout figures is that specific groups of the population will refrain from participating, with as a result that their interests and preferences do not receive all that much policy attention (Lijphart 1997). In this study, we distinguish between voters who would continue to turn out if it would not be compulsory (willing voters), voters who are doubtful about their continued engagement (reluctant voters), and voters who are sure never to turn out again if they would not be obligated to do so (hostile voters). If these groups would go out and vote, public policy would be more easily compelled to give due attention to their interests, Lijphart (1997) argues. The linchpin of his reasoning, however, is that he assumes that when these groups would turn out to vote, they will indeed use their vote in an effective manner to defend their own interests.

This, however, is by no means an established fact (Jakee and Sun 2006). Selb and Lachat (2009) have argued most notably that reluctant and hostile voters, who only turn out to vote because of a legal obligation, might lack the cognitive and other resources to cast a meaningful vote. Or, in the words of Jensen and Spoon (2011: 702): 'there is good reason to believe that requiring people to vote will bring different types of voters to the ballot box than 
a non-compulsory increase in voter turnout'. Since the levels of political sophistication of reluctant and hostile voters are quite low to start with, they are less successful in correctly identifying the political party that is closest to their own political preferences. Not to put too fine a point on it: their reasoning is that compulsory voting might lead to higher turnout, but these newly enlisted voters most often will produce mere noise because they lack the skills and the motivation to articulate a clear electoral signal about their political preferences. The end result will be that compulsory voting does not make the election result more representative than without such a legal obligation. A potential weakness of the study of Selb and Lachat, however, is that their conclusions are based on just one electoral cycle in one country, so that their results are vulnerable for momentaneous effects. In fact, the literature assumes that if compulsory voting has any effects, they might to a large extent be conditional upon on country and election characteristics. Therefore, this study will extend their study to multiple electoral cycles using data of the most recent available election studies. Moreover, to control for the fact that the results might be context-dependent, data of two different countries that stand out because of their strongly enforced system of compulsory voting will be used.

The standard practice to investigate the consequences of compulsory voting is to compare countries with and without such a legal system. While this is certainly feasible (Quintelier et al. 2011), this approach also creates some problems of its own, as there is a vast array of systems where the legal obligation could be just in the books, or is actually enforced. While, e.g., a number of countries in Latin America have a legal obligation to vote in their electoral laws, in practice there seems to be a huge amount of variation, even with regard to the local application of these laws (Birch 2009). Another approach, however, is to look more specifically at countries where compulsory voting is actually well-established, and where electoral survey research allows us to distinguish willing voters, and reluctant and hostile voters, who vote mainly because of the obligation. Earlier studies have shown that these groups of reluctant and hostile voters are mainly lower educated, with lower levels of political interest and political knowledge (Birch 2009). Previous research has shown that the impact of individual-level determinants of turnout is contingent on the specific regulation of compulsory voting (Carreras and Irepoglu 2013; Gallego 2010). According to Singh (2014: 548), this can be explained by the fact that compulsory voting alters the individual decision calculus - i.e., it raises the costs of abstaining. His conclusion is that 'many of the demographic, socio-economic and political factors known to correlate with turnout play a relatively weak role in motivating electoral 
participation where voting is mandatory'. Furthermore, he finds this effect of compulsory voting is strongest in those systems in which the compulsion is actually enforced.

However, one always has to be careful in dealing with survey questions about hypothetical behaviour. Nevertheless, both with regard to background characteristics as with regard to political attitudes, the group that indicates they would no longer vote perfectly matches the group that refrains from voting in a voluntary system. When the Netherlands first held elections without compulsory voting in 1971, one did indeed observe a very sharp decline in voter turnout, especially among the lowly educated and those with the lowest levels of political interest (Irwin 1974). In addition to the existing body of comparative research on the effects of compulsory voting, it therefore also makes sense to investigate these effects in a more in-depth manner in countries that offer an ideal setting with regard to the effectiveness of compulsory voting.

More specifically, the main research question is to determine whether the groups of reluctant and hostile voters, cast an ideologically congruent vote. There are indeed solid reasons to doubt this assumption: all available research suggests that those with the lowest levels of political sophistication are most likely to abandon voting if this is no longer compulsory (Dassonneville \& Hooghe, forthcoming). Simultaneously, political sophistication is a key resource in order to cast an ideologically congruent vote that accurately reflects the preferences and opinions of the citizens (Delli Carpini and Keeter 1996). Higher levels of political sophistication (i.e., political interest, knowledge, or a higher level of education) help voters to identify in a correct manner the political party or the candidate that is closest to their own political preferences and thus the most ideologically congruent (Lau et al. 2014). A counterargument to the Australian system of compulsory voting might therefore be that large groups of the population will be compelled to vote, but that they will do so in a non-informed manner.

\section{Congruence of the vote}

The assumption is thus that compulsory voting leads to a non-informed vote, and in practice this can be operationalised by investigating the congruence of the vote. Congruence of the vote stands for the extent to which voters cast a vote that is as close as possible with their own points of view (Ray 1999). This concept has an important role in for instance the literature on 'correct voting' (Lau and Redlawsk 1997; Lau et al. 2008; Lau et al. 2014). In this literature, a 'correct' vote is defined as the vote that the voter would have casted if s/he would have disposed of full information about the political system (Lau and Redlawsk 1997). The ideal voter should 
compare the policy positions of all political parties, to determine in a correct manner what political party is closest to her/his own preferences. Sincere voting, that is not being hampered by strategic or other considerations, should lead to a vote for that specific, closest party. Other approaches towards voting behaviour also exist - for instance the directional theory of voting (Rabinowitz and Macdonald 1989) - but given the theoretical interest this study uses the spatial logic, in line with previous research on the quality of the vote, as it can be assumed that the directional character of the vote is not related to quality of the vote (Lau et al. 2014). In empirical studies, this can be investigated by matching the positions of voters with those of the parties they voted for. One of the possible ways to measure the extent to which voters cast a vote that is congruent with their views is by examining the distance between the voter and the party s/he voted for on the classical ideological left-right axis. Although it has to be acknowledged that numerous policy dimensions could be distinguished, a rather straightforward left-right classification not only has the advantage that it can be compared across countries and time, it also has been shown that a left-right division summarises the meaningful issues in the political debate for a vast majority of citizens (Benoit and Laver 2007; McAllister et al. 2015).

Ideological congruence with a party has been investigated since the first spatial models of vote choice (Downs 1957), and is an often used measure of the parallel between a voter's and a party's positions (Martin et al. 2014). Wagner, Johann and Kritzinger (2012: 379), for instance, use ideological congruence as a way to investigate the democratic 'quality' of the vote: 'the greater the ideological similarity between a voter and the party she chooses, the higher the quality of vote choice'. While there might be reasons not to cast a vote for the closest political parties (personal voting, strategic voting, ...) the representative goal of elections does require that there is a high level of congruence between the positions of citizens and the politicians they vote for. It has been argued, therefore, that congruent voting is an essential prerequisite for the democratic quality of the electoral process:

If "the will of the people" is achieved in a democracy in large part by citizens electing representatives who share their own values and priorities, that mechanism can only work if citizens actually choose those parties or candidates who do indeed best represent their own views. Incorrect votes undermine democratic representation by helping to elect officials who do not accurately represent the views of their voters, and by misleading other government officials who might try to assess public opinion based on those election results (Lau et al. 2014: 240). 
Voting behaviour that deviates from the closest political party might interfere with the representative function of elections, and therefore in this study ideologically congruent voting will be used as the dependent variable in the analysis. The hypothesis states that those who see the legal obligation as their main, if not only motivation to cast a vote, will be less able to cast a congruent vote. This expectation was already investigated by Jensen and Spoon (2011). In their study, they find that governments span a wider ideological range in countries that have high turnout as a result of compulsory voting laws, suggesting the match between voters and parties is less close in these countries. Therefore it is expect that there is an impact of compulsory voting on ideological congruence at the individual level as well. It has to be noted, however, that this leads to two distinct research question. The first is determining what would be the electoral consequences if a large group of the population would no longer participate in elections. This calls for a simulation approach, without all that much control variables. Second, to identify the causal mechanism that is responsible for these differences, additional control variables are added in a fully specified multivariate model. Since both research questions are theoretically relevant, both of them will be addressed in this article.

\section{Data and methods}

This study investigates the impact of compulsory voting on the ideological congruence of the vote in two countries that obligate turning out on Election Day: Australia and Belgium. Not only are this two countries with exceptionally high voter turnout levels, in both countries good and reliable electoral survey data are available. This allows to control for the fact that the results might be context-dependent by comparing the results of two countries that are comparable with regard to the compulsory voting system. To further increase the robustness of the findings, evidence from more than one electoral cycle will be used, in order to avoid time-specific findings. In this way, the results that previous research has found (Selb and Lachat 2009) are put to a more profound test.

For the Australian analyses the data of the Australian Election Study are used. More specifically, the studies conducted in 2007, 2010, and 2013. In 2007, a stratified systematic random sample was drawn from the Commonwealth Electoral Roll. The selected respondents received a questionnaire by mail and were asked to fill in and return the survey by mail. In total, 1,879 of the 5,000 distributed surveys were completed and filed (Bean et al. 2007). Also in 2010, a stratified systematic random sample was drawn, the selected respondents of which 
received a questionnaire by mail. In this election year, 2,003 of the 4,999 selected respondents filled in the questionnaires. Given the underrepresentation of the younger age groups, an additional online survey was set up to adjust for this bias, resulting in a total of 2,214 valid surveys (McAllister et al. 2010). Finally, in 2013, 3,379 of the 12,200 contacted respondents answered by mail or filled in the questionnaire online (Bean et al. 2013). The Australian Election Study offers a good and reliable view of Australian voters and their motivations.

In Belgium, the data assembled by the PartiRep research group in both the election years of 2009 and 2014 are used. In 2009, a geographically stratified sample of eligible voters was drawn for the National Register. 2,331 of the 4,831 selected respondents were interviewed face-to-face in the months before Election Day on 7 June 2009. Still before Election Day, a second wave of (phone-) surveys was executed among the same respondents, in which 1,845 respondents participated. Finally, 1,698 of those respondents also participated in the third survey wave, conducted in the weeks after Election Day. In 2014, a new sample was drawn using the same methodology. In this year, respondents were interviewed face-to-face before the elections of 25 May once, and by telephone after the elections. While 2,019 of the 4,511 selected respondents took part in the first wave, 1,532 also participated in the post-electoral wave. $^{2}$ For the Belgian context too, the PartiRep surveys can be considered as state of the art in electoral research.

\section{Dependent variable}

The dependent variable in this study is the congruence of the vote. As Lau et al. (2014) state, ideological self-identification acts as a measure that provides insight in the policy considerations of the voter. Therefore, the distance between the ideological self-placement of the respondent on the left-right axis and the placement of the party the voter voted for is calculated, and this for every respondent in the data. For the position of the voter, the selfreport of respondents indicating their position on the axis on which 0 indicates political left and 10 stands for political right is used. This question was included in all five the surveys that are being used, so this left-right placement indeed allows for a comparison between the two countries under investigation.

In the literature, there are two major traditions on how to assign an ideological position to political parties. While some authors rely on expert placements, others prefer placements by public opinion. However, these two measures are shown to correlate to a large extent (Bakker 
et al. 2015; Dalton and McAllister 2015), and this study will therefore follow the same methodology as most previous studies on ideological congruence and use respondent's assigned party positions (Dalton and McAllister 2015; Dassonneville and Dejaeghere 2014; Kölln and Polk 2016; Powell 2009). Therefore, the mean placement of every party is calculated by averaging the respondent's assignments and using this average as the party position. Only in the PartiRep study of 2009 , however, respondents were not asked to position the Belgian parties on the left-right axis. Therefore, for the analysis on the 2009 Belgian data, the positions of expert respondents of the Chapel Hill Expert Survey is used to place all parties on the ideological axis. We use the data of 2010 (Bakker et al. 2015) since data for 2009 are not available. To test whether this way of assigning the position to the parties is reliable, the respondents' positioning are compared with the Chapel Hill positions in 2014. The correlation between the two sources of ideological positions is 0.96, indicating that using the Chapel Hill data is a reliable way to position the Belgian parties in 2009. The very high correlation indicates that there is no meaningful difference between the scores assigned by voters, and the scores assigned by the experts in this case and this adds validity to the method this study used to assign party positions.

Figure 1. Ideological Positions of the Political Parties, for every election cycle

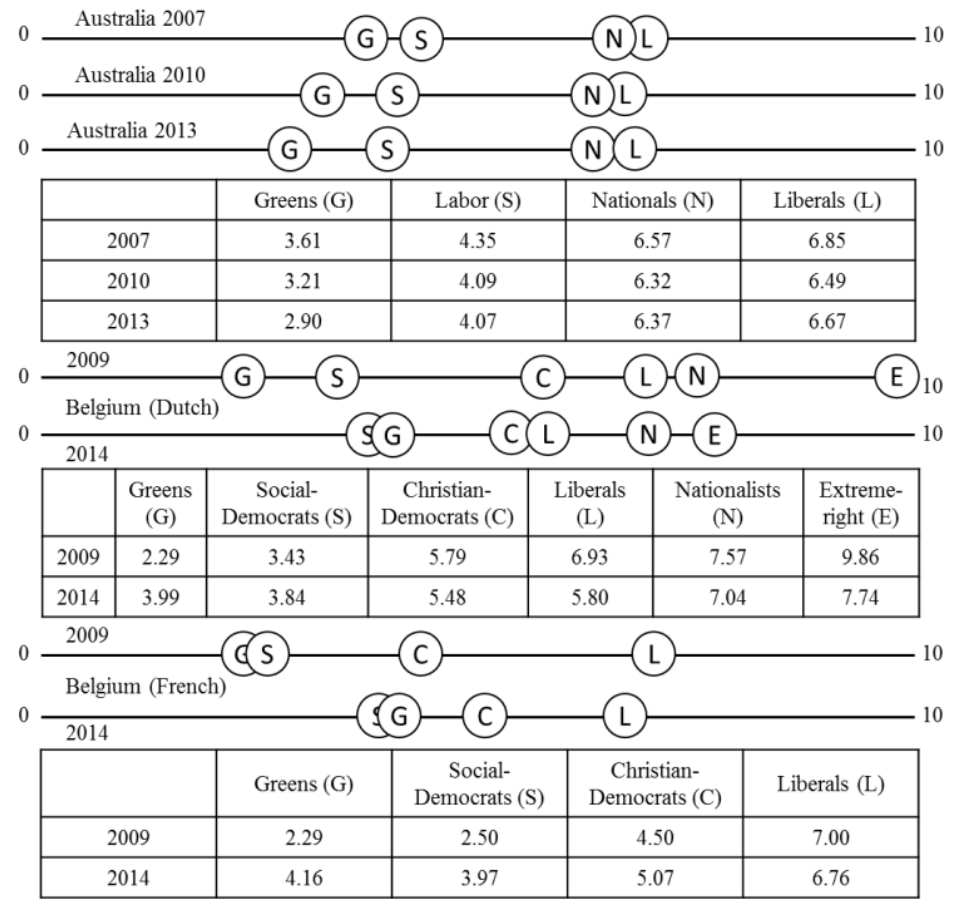


In the next step, the congruence of the vote is calculated by subtracting the ideological position of the party the respondent voted for from the respondents' self-placement. The absolute value of this difference is our dependent variable. While it needs to be recognised that this is a rather 'crude' way to measure congruence, it is the common approach in the literature (Lau et al. 2014). Furthermore, while it might be considered a very limited operationalisation of political congruence, its simplicity also renders it more suitable for this kind of comparative research as the left-right dimension can be seen as a basic structuring element for different party systems. While this left-right self-placement might entail various measurement errors, comparative research suggests that it does remain useful as a valid manner to classify voters and parties (Knutsen 1998). Table 1 provides an overview of the distribution of the congruence of the vote. As can be observed, the average incongruence of the vote is substantially the same in the two countries and the different elections in every country, so that there is a sufficient level of variance that can be explained.

Table 1. Descriptive statistics of the dependent variables

\begin{tabular}{ccccc}
\hline Study & Mean & Std. Dev. & Minimum & Maximum \\
\hline Australia 2007 & 1.833 & 1.720 & 0.154 & 7.846 \\
Australia 2010 & 1.568 & 1.217 & 0.089 & 6.787 \\
Australia 2013 & 1.621 & 1.267 & 0.065 & 6.665 \\
Belgium 2009 & 1.811 & 1.383 & 0.000 & 9.860 \\
Belgium 2014 & 1.476 & 1.326 & 0.005 & 7.041 \\
\hline
\end{tabular}

Entries: mean ideological distance between voter and party in five electoral surveys. Source: AES 2007, 2010, 2013; PartiRep 2009, 2014.

\section{Independent variables}

The independent variable of interest is an indication of whether or not the respondent would still turn out to vote if this was not obligatory anymore. The answers on this question provide insight in the difference of the congruence of the vote between those respondents who turn out voluntarily and those who only do because they are obligated to do so. The study thus relies on self-reported hypothetical behaviour. As Jackman (1999) states, this might result in an overreported engagement to turn out. This can be caused by the social desirability of reporting continued engagement, or by the fact that the most engaged citizens are also most prone to take part in surveys. However, previous research has indicated that the answers on these questions provide results that are comparable to what one would expect in a system with voluntary turnout (Hooghe and Pelleriaux 1998). The focus is mainly on the groups of voters that would no longer vote without compulsory voting, and we distinguish voters that seem to be reluctant 
to turn out, and hostile voters who are convinced that they would not turn out anymore. Most likely, these groups are underrepresented in this kind of survey research, thus leading to a conservative test of the hypotheses on these groups.

In the Australian Election Studies, the respondents were asked: 'Would you have voted in the election if voting had not been compulsory?' - the answer categories to choose from were 'definitely would have voted', 'probably would have voted', 'might, might not', 'probably not' and 'definitely not'. In the Belgian studies, this willingness to vote was measured with the question: "If voting for the Parliament was not compulsory anymore in Belgium, would you turn out to vote always, most of the times, sometimes or never?' - in 2014 the reference to 'the Parliament' was dropped, and the question was probed for the different levels of governance separately. To make the results comparable, the answers about turnout for the national Parliamentary elections are used. It becomes apparent that while the Australian surveys probed the hypothetical behaviour in the past election, the Belgian surveys aim at future behaviour, as there is indeed an ongoing debate in Belgian politics about an abolishment of the system. However, both measurements tap the persistent willingness to turn out in the hypothetical setting of voluntary turnout. Table 2 provides an overview of the answers on these questions of the different studies in the different countries.

Table 2. Distribution of the variable probing hypothetical turnout

\begin{tabular}{lccc}
\hline Hypothetical voting behaviour & $\begin{array}{c}\text { Australia } 2007 \\
(\%)\end{array}$ & $\begin{array}{c}\text { Australia 2010 } \\
(\%)\end{array}$ & $\begin{array}{c}\text { Australia 2013 } \\
(\%)\end{array}$ \\
\hline Definitely not (hostile voters) & 1.73 & 2.20 & 2.00 \\
Probably not (hostile voters) & 3.64 & 4.41 & 5.48 \\
Might, might not (reluctant voters) & 5.18 & 5.88 & 4.95 \\
Probably would have voted (reluctant & 15.73 & 16.67 & 18.00 \\
voters) & 73.72 & 70.85 & 69.57 \\
Definitely would have voted (willing voters) & 1,678 & 1,770 & 3,050 \\
\hline $\mathrm{n}$ & Belgium 2009 & Belgium 2014 & \\
\hline \multicolumn{5}{c}{$(\%)$} & 17.66 & \\
\hline Never (hostile voters) & 22.87 & 11.00 & \\
Sometimes (reluctant voters) & 14.44 & 15.26 & \\
Most of the times (reluctant voters) & 11.81 & 56.08 & \\
Always (willing voters) & 50.88 & 1,291 & \\
\hline $\mathrm{n}$ & 1,482 & & \\
\hline
\end{tabular}

Data: AES 2007, 2010, 2013; PartiRep 2009, 2014

As can be observed in Table 2, the majority of voters in both countries indicate a persistent engagement to turn out and cast a vote. In Australia, 74.1\% (2007), 70.9\% (2010) and 69.6\% 
(2013) of the respondents say they would definitely have voted if it would not have been compulsory, while only a small minority indicates they would probably or definitely not have voted. In Belgium, 50.9\% (2009) and 56.1\% (2014) indicate they would always turn out, also if they would not be obligated to do so. As becomes apparent, among the Belgian respondents the group of voters saying they would never turn out anymore is larger than the group of potential non-voters in Australia, while the group indicating they would always turn out is smaller. Nevertheless, in line with existing research, these distributions suggest that an abolishment of compulsory voting would indeed be associated with a strong decline in levels of voter turnout in both countries (Irwin 1974). The results suggest that this drop might be even sharper in Belgium than in Australia.

However, as also can be observed in Table 2, the distribution of the variable is skewed towards indicating a continued engagement to turn out. Although this self-report can be expected to be over-reported (Presser and Traugott 1992; Selb and Munzert 2013), it seems that voters are to a large extent willing to continue to turn out when they are not obligated to do so. By itself, there is no reason to doubt these figures. If we assume that these survey responses can help us to predict future turnout levels, if compulsory voting would be abolished, this would lead to turnout rates of ca. $70 \%$ in the Australian case, and $60 \%$ in the Belgian case, which is perfectly within the range noted in other similar countries. However, this distribution also raises the risk of the results of analyses to be biased since the estimation of the coefficients of some groups would be based on a small number of respondents. Therefore, for the Australian data, the two answer categories indicating that the respondent would not turn out are taken together. ${ }^{3}$ In this way, the categories 'definitely not' and 'probably not' are taken together to one category of hostile voters, and they always include at least five per cent of all respondents. The other answer categories are not changed, so that in both countries the turnout variable consists of four categories and this renders the comparison between both countries more straightforward. Subsequently, this variable is included in the analyses as a categorical variable. The interest is in comparing willing voters with reluctant and hostile, and consequently the willing voters are taken as reference category. In this way, these voters can be compared with those the reluctant and hostile voters, and doing so the influence of compulsory voting on the congruence of casted votes is investigated.

Furthermore, in a second step, several control variables that have an effect on voter turnout (Blais 2006) are included to examine whether the difference between the different groups of voters is not dependent on other characteristics than merely the willingness to turn out. First, we include sex (1=female) and the age of the respondent since it has been shown that 
these variables influence voting behaviour and they are routinely controlled for in electoral research (Blais 2006; Smets and van Ham 2013). Second, we control for political knowledge since it can be expected that respondents with higher levels of political knowledge are better able to identify the parties that are ideologically close to their own point of view (Delli Carpini and Keeter 1999). In Australia, knowledge was measured by presenting six statements of which respondents were asked to indicate whether they thought the statements were true or false. The political knowledge scale is constructed by adding up the number of correct answers. In Belgium, respondents were asked five factual questions and provided with four possible answers to choose from. Here as well, the number of correct answers is calculated. A score of zero is assigned to those respondents indicating not to know the answer (Jessee 2016). To make the metrics more comparable, these knowledge scales are standardised to range between 0 and 1. Third, while knowledge taps the cognitive ability to detect 'close' parties, political interest is included as an indicator of the motivation to do so (Lau et al. 2014; Luskin 1990). In Australia the respondents could indicate whether they had none, not much, some, or a good deal of interest in politics, while in Belgium the scale ranged from 0 (no interest at all) to 10 (very much interested). This variable as well is standardised to range from 0 to 1 . Fourth, it can be expected that voters who position themselves close to one of the ends of the left-right axis will cast a more incongruent vote since - as the Australian and Belgian parties are not so extreme they are rated 0 or 10 by the respondents - they do not have a party close to them. Almost by definition these extreme voters will therefore have to cross a larger ideological distance than voters who position themselves in the middle and have access to parties both on the left as on the right of their own position. Therefore, we control for ideological extremeness by rescaling the ideological position of voters so that it ranges from 0 (what was middle point 5) to 5 (when the reported position was 0 or 10). Finally, since Belgium basically consists of two separate party systems (Deschouwer 2012) we control for the region the respondent lives in $(0=$ Dutchspeaking region; $1=$ French-speaking region) in the Belgian analyses. The descriptive statistics of these variables are included in appendix A

\section{Results}

To investigate whether compulsory voting has an effect on the ideological congruence of the vote, the results of linear regression analyses are presented. Since five electoral studies in two different countries are used, the results of the five models are presented separately. Table 3 
displays the results of the analyses using the Australian data, Table 4 summarises the results of the Belgian analyses. For each election, two steps are conducted. First (Model 1), a model is estimated in which only the variable indicating the willingness to turn out is included, in order to examine whether there are differences between the groups of voters with regards to the congruence of their vote. The ideological extremeness of the voter's self-positioning is also included, since this is more of a 'mechanical' control. For that same reason, the control for the region the respondent lives is also included in the Belgian analyses. This first model helps to assess the electoral consequences of compulsory voting. Second (Model 2), the control variables are included to examine whether the differences can be attributed to specific characteristic of the voters and this fully specified model allows to explain why there would be differences between groups of the electorate.

Table 3. Regression analyses explaining congruence of the vote in Australia

\begin{tabular}{lccc}
\hline & Australia 2007 & Australia 2010 & Australia 2013 \\
\hline Sex (ref. = male) & 0.049 & 0.020 & 0.061 \\
& $(0.052)$ & $(0.045)$ & $(0.039)$ \\
Age & -0.000 & 0.001 & $0.004^{* *}$ \\
& $(0.002)$ & $(0.001)$ & $(0.001)$ \\
Political knowledge & $-0.496^{* * *}$ & $-0.658^{* * *}$ & $-0.620^{* * *}$ \\
& $(0.098)$ & $(0.084)$ & $(0.072)$ \\
Political interest & $-0.306^{*}$ & $-0.333^{* *}$ & $-0.392^{* * *}$ \\
& $(0.119)$ & $(0.108)$ & $(0.091)$ \\
Ideological extremeness & $0.476^{* * *}$ & $0.500^{* * *}$ & $0.451^{* * *}$ \\
& $(0.017)$ & $(0.014)$ & $(0.012)$ \\
Turnout (ref. = definitely would & & & \\
have voted) & & & \\
Probably would have voted & -0.034 & -0.042 & 0.069 \\
& $(0.074)$ & $(0.064)$ & $(0.053)$ \\
Might, might not & 0.096 & 0.046 & 0.008 \\
& $(0.118)$ & $(0.100)$ & $(0.093)$ \\
Probably not/definitely not & 0.108 & 0.175 & $0.197 *$ \\
& $(0.127)$ & $(0.099)$ & $(0.081)$ \\
Constant & $1.209 * * *$ & $1.256^{* * *}$ & $1.120^{* * *}$ \\
& $(0.147)$ & $(0.117)$ & $(0.097)$ \\
\hline N & 1376 & 1636 & 2863 \\
$\mathrm{R}^{2}$ & 0.376 & 0.449 & 0.336 \\
\hline
\end{tabular}

Source: AES 2007, 2010, 2013. Note: entries are unstandardized coefficients with standard errors reported between parentheses. *: $\mathrm{p}<0.05 ; * *: \mathrm{p}<0.01 ; * * *: \mathrm{p}<0.001$.

The variable of interest is whether or not the respondent would have voted if this would not have been compulsory. This is included as a categorical variable and in order to examine the effect of compulsory voting those who would definitely have voted are taken as reference category, so those who would not have voted can be compared with this inherently motivated group. As the results in Table 3 show, there do seem to be differences between those voters 
who would have turned out if it would not have been compulsory, and those who would have been more reluctant to do so. In Model 1 of each election year, the results indicate that both the reluctant as well as the hostile voters cast a significantly less ideological congruent vote. Furthermore, in two of the three election years under investigation (2007 and 2013), the group reluctant voters indicating they probably would have turned out also casted a significantly less congruent vote than the group of voters that definitely would have turned out.

However, looking at the second model presented for each election year, the significance of the effect of willingness to turn out disappears and the effect sizes decrease. Both in 2007 as in 2010 , none of the groups of willingness to vote differs significantly from another with regard to the congruence of the vote. Only in 2013, the group hosile voters casts a significantly less congruent vote in comparison with the most willing group. The covariates that are added in the second model have a significant impact on the congruence of the vote: both political knowledge as political interest have a significantly negative impact, indicating that those who hold more political knowledge and interest cast a more congruent vote.

In sum, these results indicate a mediation effect. The reluctant and hostile voters cast a less congruent vote, but this effect is almost fully mediated by political knowledge and interest: the reluctant and hostile voters have less knowledge and interest, and therefore cast a less congruent vote, and it is therefore the difference in knowledge and interest rather than the mere willingness to turn out that explains the differences between the groups. To test whether this conclusion also holds in the Belgian context, the same analyses are conducted with the Belgian data, the results of which are summarised in Table 4.

The results of the Belgian data are in line with the findings in Australia. The first models indicate that there are significant differences in congruence of the vote between willing, reluctant and hostile voters. However, these effects disappear (2009) or substantially decrease in size (2014) when the control variables are added. Thus, this again indicates that the impact of the willingness to turn out on the congruence to vote is mediated by political knowledge and political interest and these two variables explain why the reluctant and hostile voters are significantly different from the willing voters. 
Table 4. Regression analyses explaining congruence of the vote in Belgium

\begin{tabular}{|c|c|c|}
\hline & Belgium 2009 & Belgium 2014 \\
\hline \multirow{2}{*}{ Language (ref. $=$ Dutch) } & -0.090 & $0.140^{*}$ \\
\hline & $(0.072)$ & $(0.057)$ \\
\hline \multirow{2}{*}{ Sex $($ ref. $=$ male $)$} & -0.008 & 0.099 \\
\hline & $(0.074)$ & $(0.058)$ \\
\hline \multirow{2}{*}{ Age } & -0.001 & 0.003 \\
\hline & $(0.002)$ & $(0.002)$ \\
\hline \multirow{2}{*}{ Political knowledge } & $-0.502 * * *$ & $-0.295 * *$ \\
\hline & $(0.113)$ & $(0.110)$ \\
\hline \multirow{2}{*}{ Political interest } & -0.285 & $-0.542 * * *$ \\
\hline & $(0.175)$ & $(0.127)$ \\
\hline \multirow{2}{*}{ Ideological extremeness } & $0.077 * *$ & $0.568 * * *$ \\
\hline & $(0.026)$ & $(0.019)$ \\
\hline \multicolumn{3}{|l|}{ Turnout (ref. = always) } \\
\hline Most of the times & -0.080 & 0.042 \\
\hline \multirow{2}{*}{ Sometimes } & 0.228 & 0.164 \\
\hline & $(0.110)$ & $(0.096)$ \\
\hline \multirow{2}{*}{ Never } & 0.115 & $0.378 * * *$ \\
\hline & $(0.100)$ & $(0.086)$ \\
\hline \multirow{2}{*}{ Constant } & $2.132 * * *$ & $0.605 * * *$ \\
\hline & $(0.159)$ & $(0.125)$ \\
\hline $\mathrm{N}$ & 1482 & 1290 \\
\hline $\mathrm{R}^{2}$ & 0.034 & 0.432 \\
\hline
\end{tabular}

Source: PartiRep 2009-2014. Note: entries are unstandardized coefficients with standard errors reported between parentheses. *: $\mathrm{p}<0.05 ; * *$ : $<0.01 ; * * *: \mathrm{p}<0.001$.

In conclusion, the results thus indicate that there is an impact of compulsory voting on the congruence of the vote, since reluctant and hostile voters cast a less congruent vote than those voters who would be willing to continue to turn out. This difference can mostly be explained by the different levels of political knowledge and interest between these groups. The analyses were also conducted on a pooled dataset, including the data of all elections years of the countries respectively. The results are summarised in appendix B and they also show the mediation effect of knowledge and interest - although the main effects of willingness to vote remain significant in the full models as well.

This mixed observation, however, raises the question whether the results of the elections on the aggregate level would change if there would be no compulsion to vote: now it has been established that the reluctant and hostile voters are less successful in casting a congruent vote, the question becomes whether this in fact leads to election results that reflect less adequately the ideological preferences of the population. To examine this question, three distinct steps are taken. First, every respondent is assigned to the party s/he is closest to on the ideological axis, and thus should have voted for if s/he casted the most congruent vote possible. Second, the results as reported by only the willing voters are presented. Since there are two 
categories that indicate a probable continued engagement ('definitely' and 'probably'), the results are presented with only the first group and with the two groups together respectively. Third, the results as reported by all respondents in the data are presented, including the reluctant and hostile respondents. These steps are only performed for the Australian data: Belgium's highly fragmented party system renders this kind of hypothetical calculation unfeasible as some political parties mathematically are excluded from ever being the 'closest' party. The results for Australia are summarised in Table 5.

Table 5. 'Ideal' and reported results for the different Australian elections

\begin{tabular}{|c|c|c|c|c|c|}
\hline & Party & $\begin{array}{l}\text { 'Ideal' vote } \\
\text { share }\end{array}$ & $\begin{array}{l}\text { Willing voters } \\
\text { ('definitely') }\end{array}$ & $\begin{array}{c}\text { Willing voters } \\
\text { ('definitely' + } \\
\text { 'probably') }\end{array}$ & All voters \\
\hline \multirow{4}{*}{ 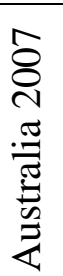 } & Greens & $18.03 \%$ & $8.27 \%$ & $7.96 \%$ & $8.51 \%$ \\
\hline & Labor Party & $47.54 \%$ & $46.68 \%$ & $47.19 \%$ & $47.10 \%$ \\
\hline & National Party & $8.64 \%$ & $5.00 \%$ & $4.62 \%$ & $4.41 \%$ \\
\hline & Liberal Party & $25.79 \%$ & $40.05 \%$ & $40.23 \%$ & $39.97 \%$ \\
\hline \multirow{4}{*}{ 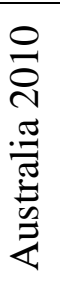 } & Greens & $19.89 \%$ & $9.73 \%$ & $9.62 \%$ & $10.45 \%$ \\
\hline & Labor Party & $47.13 \%$ & $42.90 \%$ & $43.12 \%$ & $43.43 \%$ \\
\hline & National Party & $9.27 \%$ & $3.99 \%$ & $4.20 \%$ & $4.10 \%$ \\
\hline & Liberal Party & $43.71 \%$ & $43.38 \%$ & $43.06 \%$ & $42.02 \%$ \\
\hline \multirow{4}{*}{ 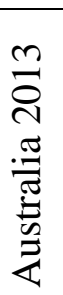 } & Greens & $23.33 \%$ & $10.79 \%$ & $10.82 \%$ & $10.54 \%$ \\
\hline & Labor Party & $40.88 \%$ & $33.98 \%$ & $35.38 \%$ & $36.77 \%$ \\
\hline & National Party & $8.68 \%$ & $4.24 \%$ & $4.27 \%$ & $4.24 \%$ \\
\hline & Liberal Party & $27.11 \%$ & $50.99 \%$ & $49.53 \%$ & $48.45 \%$ \\
\hline
\end{tabular}

Data: AES 2007, 2010, 2013. Entries are vote shares that the parties should obtain if every voter casts the most congruent possible vote (column 1), and subsequently the vote shares the parties receive of the different groups of willing voters (columns 2 to 4 ).

The results in Table 5 show that, on the aggregate level, there are no major differences between the vote choice as reported by the different groups of voters. In some instances, the group of willing voters reports a proportion of the vote that is closer to the results as they should be when every voter casts the best possible congruent vote, in other instances the proportion of all voters comes closer to this 'ideal' vote share. Therefore, it can be concluded that, although there are differences between the different groups of voters with regard to the congruence of 
their vote, overall the results would not change that much if voting were not compulsory anymore. While the reluctant and hostile voters add a margin of error, there does not seem to be a systematic bias in their votes, with as a result that the error seems randomly distributed.

\section{Discussion}

One of the main arguments against compulsory voting is that if the political system forces its citizens to cast a vote, they will lack the motivation or the resources to do so in a meaningful manner. If these reluctant or even hostile voters therefore cast their vote in a rather random manner, the electoral process itself does not become more representative of the preferences of the population as a whole. Lau et al. (2014: 240) therefore state: 'No level of turnout can compensate for relatively high levels of incorrect voting'.

The main question of this paper was to determine whether this fear was empirically founded. Previous studies on this topic either relied on comparisons between countries with and without compulsory voting, or on data from just one election in one specific country. This method of course entails the risk that any findings might be due to the specific characteristics of this one election. In order to avoid this kind of risk in the current study, this study relied on five different elections in two national contexts. In this way, high quality data, from two countries that both have extremely high levels of voter turnout, could be used.

The results show that there are indeed differences between hostile, reluctant and willing voters with regard to the congruence of their vote. More specifically, those who only turn out because there is the compulsion to do so, cast a less congruent vote than those who would continue their electoral engagement. This relationship is mediated by political knowledge and interest, implying that hostile and reluctant voters have less knowledge about and interest in politics, causing them to cast less ideologically congruent votes. However, the possibility that hostile and reluctant voters might cast an incongruent vote as a signal also needs to be recognised, e.g., as a sign of protest against the political system, and the compulsion to vote then only adds to this feeling of resentment (Henn and Oldfield forthcoming; Singh forthcoming). When looking at the aggregate electoral results, however, the most willing voters do not get closer to what would be the proportion of 'correct' votes than does the whole electorate in the current system. Thus, while on an individual level there are differences between the current compulsory and the hypothetical situation, on the aggregate level these differences level out. A possible explanation for this finding is that hostile and reluctant voters 
- being less informed about politics - use a partisan heuristic to make up their vote choice and in doing so they apparently manage to arrive to the same vote choice as they would have if they would have been better informed. Compulsory voting, indeed, has been found to increase the level of partisanship (Dalton and Weldon 2007). Singh and Thornton (2013: 205), for instance, show that more voters identify with a party in compulsory voting systems, and this identification is strengthened by compulsory voting. Furthermore, they show that this effect is most pronounced for the least knowledgeable and the less educated voters. They conclude that 'compulsory voting engenders partisan attachments by compelling participation among those who are less politically adept and therefore more likely to search for a cue or short cut when casting their vote'. This would imply that partisanship can serve as a more powerful and effective vote choice determinant in political systems with compulsory voting and in future research it should be investigated whether this can offer an explanation for the pattern this study has found. 


\section{References}

Bakker, R., de Vries, C., Edwards, E., Hooghe, L., Jolly, S., Marks, G., Polk, J., Rovny, J., Steenbergen, M., and Vachudova, M. A. 2015. Measuring party positions in Europe: The Chapel Hill Expert Survey Trend File, 1999-2010. Party Politics 21: 143-152.

Bean, C. et al., Australian Election Study, 2007. [Computer file]. Canberra: Australian Social Science Data Archive, The Australian National University, 2008.

Bean, C. et al., Australian Election Study, 2013. [Computer file]. Canberra: Australian Data Archive, The Australian National University, 2014.

Benoit, K. and Laver, M. 2007. Estimating party policy positions: Comparing expert surveys and hand-coded content analysis. Electoral Studies 26: 90-107.

Birch, S. 2009. Full Participation. A comparative study of compulsory voting. Manchester: Manchester University Press.

Blais, A. 2006. What affects voter turnout? Annual Review of Political Science 9: 111-125.

Carreras, M. and Irepoglu, Y. 2013. Trust in elections, vote Buying, and turnout in Latin America. Electoral Studies 32: 609-619.

Dalton, R. J. and Weldon, S. 2007. Partisanship and party system institutionalization. Party Politics 13: 179-196.

Dalton, R. J., and McAllister, I. 2015. Random walk or planned excursion? Continuity and change in the left-right positions of political parties. Comparative Political Studies 48: $759-787$.

Dassonneville, R. 2012. Electoral volatility, political sophistication, trust and efficacy: A study on changes in voter preferences during the Belgian regional elections of 2009. Acta Politica 47: 18-41.

Dassonneville, R., and Dejaeghere, Y. 2014. Bridging the ideological space: A cross-national analysis of the distance of party switching. European Journal of Political Research 53: $580-599$.

Dassonneville, R., and Hooghe, M. forthcoming. Voter Turnout Decline and Stratification. Quasi-Experimental and Comparative Evidence of a Growing Educational Gap. Politics, in press.

Delli Carpini, M. and Keeter, S. 1996. What Americans know about politics and why it matters. New Haven: Yale University Press. 
Deschouwer, K. 2012. The politics of Belgium: Governing a divided society. Basingstoke: Palgrave Macmillan.

Downs, A. 1957. An economic theory of democracy. New York: Harper \& Row.

Fowler, A. 2013. Electoral and policy consequences of voter turnout: Evidence from compulsory Voting in Australia. Quarterly Journal of Political Science 8: 159-182.

Gallego, A. 2010. Understanding unequal turnout: Education and voting in comparative perspective. Electoral Studies 26: 239-248.

Henn, Matt, and Ben Oldfield. forthcoming. Cajoling or coercing: Would electoral engineering resolve the young citizen-state disconnect? Journal of Youth Studies. In Press.Hill, L. 2010. Public acceptance of compulsory voting: Explaining the Australian case. Representation 46: 425-438.

Hill, L. 2015. Does compulsory voting violate a right not to vote? Australian Journal of Political Science 50: 61-72.

Hooghe, M., and Pelleriaux, K. 1998. Compulsory voting in Belgium: An application of the Lijphart thesis. Electoral Studies 17: 419-424.

Hooghe, M. and Kern, A. forthcoming. The tipping point between stability and decline: Trends in voter turnout, 1950-1980-2012. European Political Science, in press.

Irwin, G. 1974. Compulsory voting legislation: Impact on voter turnout in the Netherlands. Comparative Political Studies 7: 292-315.

Jackman, S. 1999. Non-compulsory voting in Australia?: what surveys can (and can't) tell us. Electoral Studies 18: 29-48.

Jakee, K. and Sun, G.-Z. 2006. Is compulsory voting more democratic? Public Choice 129: $61-75$.

Jensen, C., and Spoon, J. J. 2011. Compelled without direction: Compulsory voting and party system spreading. Electoral Studies 30: 700-711.

Jessee, S. A. forthcoming. "Don't know" responses, personality, and the measurement of political knowledge. Political Science Research and Methods. doi: http://doi.org/10.1017/psrm.2015.23

Knutsen, O. 1998. The strength of the partisan component of left-right identity: A comparative longitudinal study of left-right party polarization in eight west european countries. Party Politics 4: 5-31.

Kölln, A.-K. and Polk, J. forthcoming. Emancipated party members: Examining ideological incongruence within political parties. Party Politics. doi:10.1177/1354068816655566 
Lau, R., Patel, P., Fahmy, D. and Kaufman, R. 2014. Correct voting across thirty-three democracies: A preliminary analysis. British Journal of Political Science 44: 239259.

Lau, R., and Redlawsk, D. 1997. Voting correctly. American Political Science Review 91: $585-598$.

Lau, R., and Redlawsk, D. 2006. How voters decide: Information processing in election campaigns. New York: Cambridge University Press.

Lau, R., Andersen, D. and Redlawsk, D. 2008. An exploration of correct voting in recent U.S. presidential elections. American Journal of Political Science 52: 395-411.

Lijphart, A. 1997. Unequal participation. Democracy's unresolved dilemma. American Political Science Review 91: 1-14.

Louth, J. and Hill, L. 2005. Compulsory voting in Australia: Turnout with and without it. Australian Review of Public Affairs 6: 25-37.

Luskin, R. 1990. Explaining political sophistication. Political Behavior 12: 331-361.

Mackerras, M. and McAllister, I. 1999. Compulsory voting, party stability and electoral advantage in Australia. Electoral Studies 18: 217-233.

McAllister, I., Sheppard, J. and Bean, C. 2015. Valence and spatial explanations for voting in the 2013 Australian election. Australian Journal of Political Science 80: 330-346.

McAllister, I. et al., Australian Election Study, 2010. [Computer file]. Canberra: Australian Social Science Data Archive, Australian National University, 2011.

Martin, A., Dowding, K., Hindmoor, A. and Gibbons, A. 2014. The opinion-policy link in Australia. Australian Journal of Political Science 49: 499-517.

Powell, G.B. 2009. The ideological congruence controversy. The impact of alternative measures, data, and time periods on the effects of election rules. Comparative Political Studies 42: 1475-1497.

Presser, S., and Traugott, M. 1992. Little white lies and social science models: Correlated response errors in a panel study of voting. Public Opinion Quarterly 56: 77-86.

Przeworski, A., Stokes, S.C., and Manin, B. Eds. 1999. Democracy, accountability, and representation. Cambridge: Cambridge University Press.

Quintelier, E., Hooghe, M. and Marien, S. 2011. The effect of compulsory voting on turnout stratification patterns. A cross-national analysis. International Political Science Review 32: 396-416.

Rabinowitz, G. and Macdonald S. 1989. A directional theory of issue voting. American political Science Review 83: 93-121. 
Ray, L. 1999. Conversion, acquiescence, or delusion: The contingent nature of the partyvoter connection. Political Behavior 21: 325-347.

Selb, P. and Lachat, R. 2009. The more, the better? Counterfactual evidence on the effect of compulsory voting on the consistency of party choice. European Journal of Political Research 48: 573-597.

Selb, P., and Munzert, S. 2013. Voter overrepresentation, vote misreporting, and turnout Bias in postelection surveys. Electoral Studies 32: 186-196.

Singh, S. and Thornton, J. 2013. Compulsory voting and the dynamics of partisan identification. European Journal of Political Research 52: 188-211.

Singh, S. 2014. Compulsory voting and the turnout decision calculus. Political Studies 63: 548-568.

Singh, Shane P. forthcoming. Compulsory voting and dissatisfaction with democracy. British Journal of Political Science. In press.

Smets, K. and van Ham, C. 2013. The embarrassment of the riches? A Meta-Analysis of individual-level research in voter turnout. Electoral Studies 32: 344-359.

Wagner, D., Johann, S., and Kritzinger, S. 2012. Voting at 16: Turnout and the quality of vote choice. Electoral Studies 31: 372-383.

\section{Endnotes}

\footnotetext{
${ }^{1}$. It has to be noted that countries like Somalia, Luxembourg, Turkmenistan and Cuba report equally high turnout rates. As far as we know, however, there are no reliable voter survey data available for these countries.

${ }^{2}$. Belgium is a federal, bilingual country. Both in 2009 and in 2014 the survey was conducted in the two main regions of the country: the Dutch-speaking Flanders in the north of the country, and the French-speaking region of Wallonia in the south of the country. Together these two regions account for more than 90 per cent of the Belgian population. The survey data do not include information from the smaller bilingual region of the capital Brussels, or the German speaking minority in the east of the country.

${ }^{3}$. The analyses were also conducted without taking together these categories. The results are in line with those presented in the paper: there is an impact of willingness to vote, but this seems to be mediated by political knowledge and interest. Only in the 2007 Australian elections the expected significant differences are not found, but in this dataset the group who would 'definitely not have votes' is very small $(1.53 \%)$, limiting the variance in this variable.
} 